primary and of the secondary wave have coincided.

"If this photograph is developed by reversal, or printed, the loci of maximum transmission will indicate the regions in which the primary wave had the same phase as the modified wave, and the variations of the transmission in these loci will be approximately proportional to the intensity of the modified wave. Thus, if one illuminates the photographic record with an optical imitation of the electronic wave, only that part of the primary wave will be strongly transmitted which imitates the modified wave both in phases and in amplitudes. It can be shown that the 'masking' of the regions outside the loci of maximum transmission has only a small distorting effect. One must expect that looking through such a properly processed diagram one will see behind it the original object, as if it were in place.

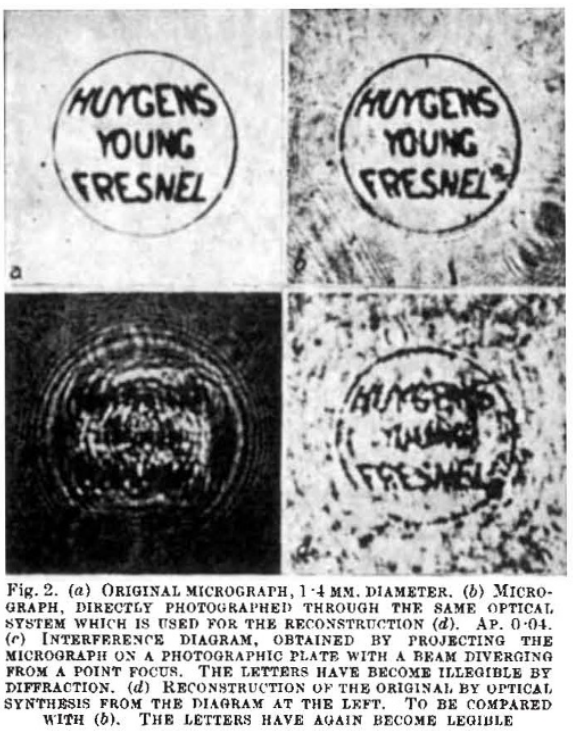

"The principle was tested in an optical model, in which the interference diagram was produced by monochromatic light instead of by electrons. The print was replaced in the apparatus, backed by a viewing lens which admitted about $\sin \alpha=0.04$, and the image formed was observed and ultimately photographed through a microscope. It can be seen in Fig. 2 that the reconstruction, though imperfect, achieves the separation of some letters which could just be separated in direct observation of the object through the same optical system. The resolution is markedly imperfect only in the centre, where the circular frame creates a disturbance. Other imperfections of the reconstruction are chiefly due to defects in the microscope objectives used for the production of the point focus, and for observation.

"It is a striking property of these diagrams that they constitute records of three-dimensional as well as of plane objects."

(From Nature, 161, $777 ; 1948$.

NOBEL PRIZE

\section{Herzberg Honoured}

The 1971 Nobel prize in chemistry has been awarded to Dr Gerhard Herzberg for his work on the electronic structures and geometries of molecules, especially free radicals. Dr Herzberg created the sound basis on which modern molecular spectroscopy is built and it was his own dynamic and enthusiastic approach to the subject which made his laboratory at the National Research Council in Ottawa a mecca for spectroscopists and his books on spectroscopy standard works of reference.

Dr Herzberg was born in Hamburg in 1904 and took a doctorate in physics at the University of Darmstadt in 1928. After two years at the University of Bristol, he returned to Darmstadt where he stayed until 1935. He then spent ten years at the University of Saskatchewan before moving to Yerkes Observatory, Chicago, in 1945. It was there that he applied his spectroscopic expertise to studies of the molecular spectra of planetary atmospheres and, with near infrared absorption techniques, he reproduced many of these spectra in the laboratory using long tubes of gas at high pressures. The period at Yerkes also saw the birth of a fruitful working relationship with Edward Teller which led to the enunciation of the Herzberg-Teller spectroscopic rules.

Although Dr Herzberg is essentially an experimentalist, he has a thorough understanding of the theoretical principles of his work which contributes to the high quality of his three books on molecular spectroscopy. His investigations of the structures of free radicals made extensive use of the technique of flash photolysis and his interest in astrophysics was further stimulated by his study of radicals such as $-\mathrm{CH}$ in the tails of comets.

Dr Herzberg's own achievements are many but his infectious enthusiasm and example must have inspired much more work than he himself has performed.

\section{SPACE \\ Goodbye to All That}

THE successful launch of the technology satellite Prospero on October 28 will in no way affect the decision to abandon Black Arrow announced in July (see Nature, 232, 363 ; 1971). The satellite was launched at 0509 BST from Woomera and went into a nearpolar elliptical orbit of 350 by 850 miles. The Black Arrow launcher worked perfectly after the one failure, one success and one partial success that make up its past history, and the experiments on board are all behaving normally. The useful life of the satellite will be between six months and a year, during which equipment for future space vehicles will be tested and a scientific experiment to measure the incidence of micrometeoroids-designed at the University of Birmingham-will be conducted.

Prospero-otherwise known as $\mathrm{X} 3$ is the second entirely British satellite to go into orbit, the first being the scientific satellite Ariel 3 in May 1967, but Prospero is the first to go up on a British launcher. The only other satellite at present planned under the national space technology programme is $\mathrm{X} 4$ which is due to be launched in 1974 on an American Scout rocket from the United States Western Test Range. Otherwise Britain's national space programme hangs fire until the government's review of it is completed early next year, although the scientific space research programme continues with the launch of UK-4 (Ariel 4), expected at the end of this month.

The decision to abandon Black Arrow was not taken because of the failure of the early launches so much as because the launcher was too small to put more than a low orbiting satellite into space and because of the high cost of the infrequent launches of the rocket. The average cost per launch of Black Arrow has been about $£ 2$ million whereas NASA will launch X4 for Britain for $£ 1.25$ million. Where the future of Britain's satellite programme may well lie-if it is to have a future-is in the larger geostationary satellites which cannot easily be launched from Woomera but which can be put into space from the USA. Hawker Siddeley, BAC and Marconi are at present studying designs of geostationary technology satellites (GTS).

Meanwhile Britain's active rocket engine industry is confined to supplying Skylark to ESRO and supplying Blue Streak to ELDO on a commercial basis -Britain having effectively withdrawn from ELDO by refusing to support an extension of it in 1968 and limiting commitment to $£ 11$ million from January 1, 1969 . Further, it is most unlikely that Britain will attempt to develop a new launcher alone but will instead concentrate the limited money available about $£ 4.6$ million a year at present-into British satellites launched from the United States. There is as yet no firm agreement with NASA that American rockets will be available to launch British satellites after $\mathrm{X} 4$ but suggestions that such an agreement may not materialize meet with bland assurances that there will be no problem.

Apart from Britain's own satellite work there is the possibility of British involvement in the post-Apollo programme, and both Hawker Siddeley and BAC are studying precisely what con- 